\title{
Amelogenin: A Potential Regulator of Cementum-Associated Genes
}

Hema L. Viswanathan, ${ }^{*}$ Janice E. Berry, ${ }^{*}$ Brian L. Foster, ${ }^{\dagger}$ Carolyn W. Gibson, ${ }^{\ddagger}$ Yong Li, ${ }^{\ddagger}$ Ashok B. Kulkarni,§ Malcolm L. Snead,

Background: Studies suggest that enamel matrix proteins induce differentiation and mineralization of a variety of mesenchymal cells, including odontoblasts, osteoblasts, and cementoblasts. It has been postulated that this activity could be due to amelogenin-like proteins, known to be present in some mixtures of enamel matrix derivatives. Amelogenins have been reported to induce expression of a mineralized tissue-specific marker, bone sialoprotein (BSP), indicating that epithelial products can regulate the activity of mesenchyme-derived cells.

Methods: To explore the molecular mechanisms involved in BSP regulation, a clonal population of immortalized murine cementoblasts (OCCM-30) was exposed to full-length murine amelogenin protein ( $\mathrm{rp}(\mathrm{H}) \mathrm{M} 180), 0.1 \mu \mathrm{g} / \mathrm{ml}$ to $10.0 \mu \mathrm{g} / \mathrm{ml}$, for 8 days in vitro. To further investigate the potential epithelial-mesenchymal interaction, an amelogenin knockout mouse model was used to examine expression of BSP and other markers, including Type I collagen, in tissue samples.

Results: The lowest dose of amelogenin slightly enhanced BSP expression, whereas at the highest dose, a dramatic decrease (three-fold) in BSP expression was observed. Parallel experiments showed a corresponding decrease in mineral nodule formation in vitro for cells treated with the higher dose of $\mathrm{rp}(\mathrm{H}) \mathrm{M} 180$. In situ hybridization and immunohistochemical analysis of sections from amelogenin null mice revealed a dramatic reduction in expression of BSP mRNA and protein in cementoblasts and surrounding osteoblasts in comparison to age-matched controls. In contrast, the expression of Type I collagen was not significantly different from controls.

Conclusion: These data suggest that amelogenin may be a critical signaling molecule required for appropriate development of the periodontium. J Periodontol 2003;74:1423-1431.

\section{KEY WORDS}

Amelogenin; animal studies; cells, mesenchyme-derived; cementoblasts; enamel matrix derivative; epithelialmesenchymal interactions; periodontium/anatomy and histology; sialoglycoproteins, bone.

\footnotetext{
* Department of Periodontics, Prevention and Geriatrics, University of Michigan School of Dentistry, Ann Arbor, MI.

$\dagger$ Department of Periodontics, University of Washington School of Dentistry, Seattle, WA.

† Department of Anatomy and Cell Biology, University of Pennsylvania School of Dental Medicine, Philadelphia, PA.

$\S$ Functional Genomics Unit, National Institute of Dental and Craniofacial Research, NIH, Bethesda, MD.

\| Center for Craniofacial Molecular Biology, University of Southern California School of Dentistry, Los Angeles, CA.

II Currently, Department of Periodontics, University of Washington School of Dentistry; previously, Department of Periodontics, Prevention and Geriatrics, University of Michigan School of Dentistry.
}

Tooth development is a complex process, regulated by a series of interactions between epithelial and mesenchymal cells. These interactions are mediated by families of molecules such as bone morphogenetic protein (BMP), Hedgehog (Hh), Wnt, and fibroblast growth factor (FGF) ${ }^{1-4}$ For example, many of the critical factors secreted by epithelial cells in the developing tooth germ are directed towards target cells of ectomesenchymal origin. The resultant signaling cascade initiates key events in the process of tooth development, ${ }^{3,5}$ such as the formation of dentin and enamel. This progression involves complex interactions between inner enamel epithelial cells (that differentiate into ameloblasts) and dental papilla cells (that differentiate into odontoblasts). However, it is unclear whether similar epithelial-mesenchymal interactions mediate later stages in tooth development, including root and periodontal ligament formation. Several laboratories have suggested that enamel matrix proteins may have a potential role in modulating root formation, ${ }^{6-10}$ and this hypothesis resulted in the development of enamel-derived products for use in therapy targeted at regenerating periodontal tissues. Subsequently, studies from our laboratory and others have shown that periodontal cells are responsive to porcine enamel matrix derivatives, both in vitro and in vivo. ${ }^{11-16}$ An enamel matrix derivative is predominantly comprised of amelogenin and processed amelogenins, along with small amounts of other enamel proteins, suggesting a role for amelogenins as regulatory molecules 
that can target periodontal cells, namely cementoblasts, periodontal ligament (PDL) cells, and dental follicle cells.

Amelogenin, the major protein component of enamel, belongs to a family of proteins formed as a result of alternative splicing of a single primary transcript. ${ }^{17}$ The human amelogenin gene is found on both $X$ and $\mathrm{Y}$ chromosomes, but mice only have a single gene. ${ }^{18}$ The most abundant amelogenin expressed by mouse ameloblasts consists of 180 amino acids and possesses the ability to undergo self-assembly, which contributes to biomineralization of enamel. ${ }^{19,20}$ Recent data suggest a role for amelogenin beyond regulation of crystal growth. For example, Nebgen et al. ${ }^{21}$ reported that amelogenin-polypeptides in dentin matrix induced chondrogenic activity and, using an in vivo model, ${ }^{22}$ Veis and colleagues demonstrated that smaller splice variants of amelogenin (known as leucine-rich amelogenin peptides or LRAPs) increased the expression of certain bone-specific markers. These amelogenin gene splice products were termed $r[\mathrm{~A}+4]$ and $r[\mathrm{~A}-4]$ and represent peptides obtained from amelogenin cDNA with or without exon 4, respectively. Both $r[A+4]$ and $r[A-4]$ induced expression of BAG-75 (bone acidic glycoprotein-75) and BSP. BSP is a non-collagenous protein component of mineralized tissues believed to be a critical molecule for promoting biomineralization. ${ }^{23}$ Importantly, with regard to root development, the temporal and spatial expression of BSP, both mRNA and protein, parallels the deposition of cementum along the root surface. ${ }^{24}$ This information, coupled with preliminary findings that amelogenin null mice also exhibit cementum defects, ${ }^{25,26}$ suggests that amelogenin may have a role in the regulation of genes associated with root formation.

The primary purpose of this study was to identify the cementum-associated genes regulated by amelogenin and to begin to define the molecular mechanisms underlying these responses. Results from the studies reported here indicated that cementoblasts exposed to full-length murine amelogenin in vitro exhibited a slightly enhanced BSP expression at low doses $(0.1 \mu \mathrm{g} / \mathrm{ml})$, but a dramatic decrease in BSP expression at high doses, with a corresponding decrease in mineral nodule formation. Interestingly, BSP transcripts and proteins were barely detectable in both cementum and bone tissue recovered from the amelogenin knockout mice. Thus, BSP regulation/expression appears to be sensitive to fulllength amelogenin; however, the specific mechanism involved needs further investigation. Whether enamel matrix derivative regulates BSP by a similar mechanism remains to be defined.

\section{MATERIALS AND METHODS}

\section{Cell Culture}

Clonal populations of immortalized cementoblasts (OCCM-30) were isolated using a method described previously. ${ }^{27}$ Briefly, OC-TAg transgenic mice were obtained from Dr. Jolene Windel (Virginia Commonwealth University, Richmond, Virginia). These mice were developed using a construct that employed the $\mathrm{SV}-40 \mathrm{~T}$ antigen under the direction of the osteocalcin (OCN) promoter. ${ }^{27}$ In this situation, when cells are isolated from the tooth root surface of OC-TAg mice, only those cells that express osteocalcin (i.e., cementoblasts) are capable of surviving serial passage in vitro. The immortalized cementoblasts obtained in this manner were subcloned and the clone used in this study was designated as OCCM-30. These cells were shown to exhibit the same properties as comparable cells found in vivo, i.e., they expressed high levels of cementum-associated markers, such as BSP and OCN, and promoted biomineralization in vitro and in vivo. ${ }^{28}$ For the purpose of this study, the cells were maintained in Dulbecco's Modified Eagle medium (DMEM), supplemented with $10 \%$ fetal bovine serum (FBS), and $1 \%$ antibiotics $(100 \mathrm{U} / \mathrm{ml}$ penicillin and $100 \mu \mathrm{g} / \mathrm{ml}$ streptomycin), " Full-length murine amelogenin (rM180) was expressed in E. coli using a polyhistidine aminoterminal tag and the pQE30 expression vector** to produce recombinant, histidine-tagged protein. The expressed amelogenin was isolated and characterized as previously described ${ }^{29}$ and designated rp(H)M180.

In situ hybridization and immunostaining analysis. Murine teeth obtained from both wild-type and amelogenin knockout mice were analyzed by in situ hybridization. Briefly, amelogenin null mice were produced by disrupting the locus of the amelogenin gene. ${ }^{26}$ These mice had abnormal and discolored teeth, indicative of disorganized and hypoplastic enamel. Molars from 33-day-old mice (where day 0 is vaginal plug date) were used for in situ hybridization analysis. Standard procedures were used, with slight modifications. ${ }^{28}$ Animal care guidelines for the University of Pennsylvania were followed. Decalcified and paraffin-embedded tissue sections were mounted on silane-treated slides and prepared by rehydration, acetylation, and dehydration. These slides were then overlaid with a standard hybridization solution and hybridization was performed overnight at $50^{\circ} \mathrm{C}$ in a humid chamber, using both antisense and sense (control) RNA probes for BSP and Type I collagen ${ }^{30}$ (a gift from Dr. Marion Young, NIH/NIDCR). These probes were transcribed from cDNA plasmids, incorporating ${ }^{35} \mathrm{~S}$ $\mathrm{UTP}^{\dagger \dagger}$ (in vitro transcription kit). ${ }^{\neq}{ }^{\ddagger}$ After post-hybridization washes of increasing stringency, the slides were dehydrated and exposed to $\mathrm{x}$-ray film to determine efficiency of hybridization. Following coating with NTB-2 emulsion $\S \S$ and dark storage at $4^{\circ} \mathrm{C}$ for an appropriate

\footnotetext{
\# Invitrogen Corporation, Carlsbad, CA.

** Qiagen Inc., Valencia, CA.

$\dagger \dagger$ Amersham Pharmacia Biotech, Arlington Heights, IL.

㧊 Ambion Corporation, Austin, TX.

$\S \S$ Kodak Imaging Systems, Rochester, NY.
} 
time, slides were developed using developer $§ \S$ and rapid fixer, $₫ \S$ and were counter-stained with hematoxylin/eosin. Hybridization signal was visualized using a light microscope with a dark field condenser. For immunohistological analysis, sections from wild type and amelogenin knockout mice were deparaffinized in xylene and rehydrated to phosphate buffered saline (PBS) using serial dilutions of ethanol. Sections were pretreated as previously described. ${ }^{28}$ Experimental sections were incubated with a primary antibody (rabbit antiserum raised against mouse recombinant BSP fused to GST, a gift from Dr. Renny Franceschi, University of Michigan, Ann Arbor, Michigan) diluted 1:150 in DMEM with 5\% FBS added for 60 minutes at room temperature. Control sections not treated with primary antibody were treated simultaneously. Following incubation, a commercial histostain kit $\|$ was used to treat sections with the secondary antibody according to manufacturer's instructions. The presence of the enzyme was revealed by the addition of a substrate chromogen containing levamisole, an inhibitor of endogenous alkaline phosphatase.

\section{Cell Proliferation}

For proliferation studies, cells were seeded in 24-well plates, in triplicate, at a density of 10,000 cells $/ \mathrm{cm}^{2}$. Cells were allowed to adhere overnight and then treated with DMEM containing $2 \%$ FBS, with $0.1,1.0$, or $10.0 \mu \mathrm{g} /$ $\mathrm{ml}$ of $\mathrm{rp}(\mathrm{H}) \mathrm{M} 180$, or with $100 \mu \mathrm{g} / \mathrm{ml}$ enamel matrix derivative $(\mathrm{EMD})^{\text {Ifl }}$ as a control. Medium was changed on days 2,4 , and 6 , along with addition of appropriate concentrations of $\mathrm{rp}(\mathrm{H}) \mathrm{M} 180$ or EMD. Cells were trypsinized on days 3, 5, and 7 and quantitated using a Coulter counter."\# Experiments were repeated on three separate occasions.

\section{Adenylyl Cyclase Stimulation Assay}

Adenylyl cyclase stimulation assays were performed as described previously. ${ }^{31}$ Briefly, the OCCM-30 cells were plated in DMEM media in 24-well tissue culture plates, in triplicate, at 35,000 cells $/ \mathrm{cm}^{2}$. After 48 hours, the cells were confluent and were stimulated with vehicle, $10^{-7} \mathrm{M} \mathrm{PTHrP} * * *$ (positive control) or $0.1,1.0$, or $10.0 \mu \mathrm{g} / \mathrm{ml}$ of $\mathrm{rp}(\mathrm{H}) \mathrm{M} 180$ for 15 minutes at $37^{\circ} \mathrm{C}$ in $\mathrm{Ca}^{2+}-\mathrm{Mg}^{2+}$-free HBSS ${ }^{\#}$ containing $0.1 \% \mathrm{BSA}$ and $1 \mathrm{mM}$ IBMX (3-isobutyl-1-methyl xanthine), ${ }^{\dagger \dagger}$ a phosphodiesterase inhibitor. Intracellular CAMP was extracted and measured, using a cAMP binding protein assay. ${ }^{31}$ The cAMP levels were calculated by a log-logit method, ${ }^{\neq} \neq$normalized to cell number, and expressed as $\mathrm{pmol} / \mathrm{ml}$.

\section{Northern Blot Analysis}

Dose-dependent effects of amelogenin. Cells were seeded at an initial density of 35,000 cells $/ \mathrm{cm}^{2}$ and maintained in DMEM containing 10\% FBS. Upon confluence, cells were treated with $0.1,1.0$, or $10.0 \mu \mathrm{g} / \mathrm{ml}$ of $\operatorname{rp}(\mathrm{H}) \mathrm{M} 180$, along with $50 \mu \mathrm{g} / \mathrm{ml}$ of ascorbic acid in DMEM with $5 \%$ FBS. On day 8, total RNA was harvested using a reagent, " fractionated on a $6 \%$ formaldehyde and $1.2 \%$ agarose gel, and then transferred to a nylon membrane for analysis by Northern blotting. 32 Blots were hybridized with random-primer labeled ${ }^{32} \mathrm{P}$ probes for BSP (a gift from Dr. Marion Young, $\mathrm{NIH} / \mathrm{NIDCR}$, Bethesda, Maryland) and OCN (a gift from Dr. John Wozney, Wyeth Research, Cambridge, Massachusetts), and exposed to autoradiography film at $-70^{\circ} \mathrm{C}$ for up to 24 hours. Blots were normalized against ethidium bromide staining for 18S rRNA. Experiments were performed on two occasions. To control for non-specific effects due to protein concentration, experiments were performed using two additional proteins with molecular weights similar to rp(H)M180 amelogenin. Chymotrypsinogen ${ }^{\dagger \dagger}$ (25.6 $\mathrm{kDa})$ and ovalbumin ${ }^{\dagger \dagger}(44.3 \mathrm{kDa})$ were added at doses of $10 \mu \mathrm{g} / \mathrm{ml}$ under the same conditions as amelogenin Northern blot experiments.

Time-course experiment. To determine the time required for amelogenin to alter the expression of BSP and OCN, cells were seeded as described above and treated with $10.0 \mu \mathrm{g} / \mathrm{ml}$ of $\mathrm{rp}(\mathrm{H}) \mathrm{M} 180$ at confluence (0 hours). Total RNA was isolated at $0,0.5,3,6,12$, 24 , and 48 hours and analyzed for BSP and OCN expression by Northern blotting.

Pathway inhibitor studies. To identify the signaling pathway(s) involved in amelogenin regulation of BSP and OCN, cells were seeded and maintained as described earlier, until confluence was reached. The cells were pretreated with pathway inhibitors for 1 hour, followed by the addition of $10.0 \mu \mathrm{g} / \mathrm{ml}$ of $\mathrm{rp}(\mathrm{H}) \mathrm{M} 180$. Total RNA was isolated after an additional 24 hours. The cell-permeable adenylyl cyclase inhibitor, 9-(2-tetrahydrofuryl) adenine, THFA $\$ \S \S(100 \mu \mathrm{M})$, was used to inhibit the PKA pathway, while GF109203X§§§ (3 $\mu \mathrm{M})$, was used to block the PKC pathway.

\section{In Vitro Mineralization Assay}

Cementoblasts were seeded at 35,000 cells $/ \mathrm{cm}^{2}$ in 24 -well plates and maintained in 10\% FBS until confluent. Cells were then incubated with DMEM containing $5 \%$ FBS and rp(H)M180 $(0.1,1.0$, or $10.0 \mu \mathrm{g} / \mathrm{ml})$ and supplemented with $50 \mu \mathrm{g} / \mathrm{ml}$ ascorbic acid and $3.0 \mathrm{mM}$ $\beta$-glycerophosphate. On day 8, cells were stained using the von Kossa protocol to detect formation of mineral nodules. ${ }^{34}$ Cells were also treated with Alizarin Red-S (AR-S) to quantify the extent of mineralization. ${ }^{35}$ Fixed cells were stained with AR-S dye, which specifically stains calcified nodules. The AR-S was then eluted from the

||| Zymed, San Francisco, CA

ขी Emdogain, Biora AB, Malmö, Sweden.

\#\# Beckman-Coulter, Fullerton, CA.

*** Bachem California, Inc., San Francisco, CA.

$\dagger \dagger \dagger$ Sigma Corporation, St. Louis, MO.

$\neq \neq \neq$ GraphPad Software Inc., San Diego, CA.

$\S \S \S$ Biomol Reseach Laboratories, Plymouth, PA. 
mineral and measured spectrophotometrically. Using a standard absorption curve, the concentration of the eluted dye for each experimental group was determined. Eluted dye concentration could be related directly to the concentration of $\mathrm{Ca}^{2+}$ for each sample, providing a quantitative indication of the extent of mineral formation.

\section{Statistical Analysis}

All experiments were performed a minimum of two times with comparable findings obtained. For cAMP stimulation assays, a Student's $t$ test was conducted to analyze the results. For mRNA measurements and proliferation studies, the data were analyzed by either ANOVA followed by a Tukey-Kramer multiple comparison test or a Student's $t$ test as needed. For Northern blot analyses, representative autoradiographs are shown with a graphical analysis demonstrating statistical evaluation of multiple assays.

\section{RESULTS}

\section{In situ Hybridization and Immunostaining Analysis}

In situ hybridization analysis of tissue obtained from age-matched wild-type controls and amelogenin knockout mice is shown in Figure $1 \mathrm{~A}$. BSP is strongly expressed by cells along the tooth root surface (cementoblasts) and in alveolar bone (osteoblasts) in the wildtype sample, whereas hybridization signals are markedly reduced in the amelogenin null mouse. However, Type I collagen mRNA levels appeared to be similar in both wildtype and null mouse. This was further indicated by immunostaining results (Fig. 1B) showing reduced expression of BSP protein along the root surface and alveolar bone in sections from the null mouse in comparison to wild-type. These combined results suggest that amelogenin may be a key regulator of BSP, a protein considered to be required for development of cementum.

\section{Cell Proliferation Assays}

Enamel matrix derivative, which is stated to be a mixture of mostly amelogenin proteins, is known to enhance

\section{Figure 1 .}
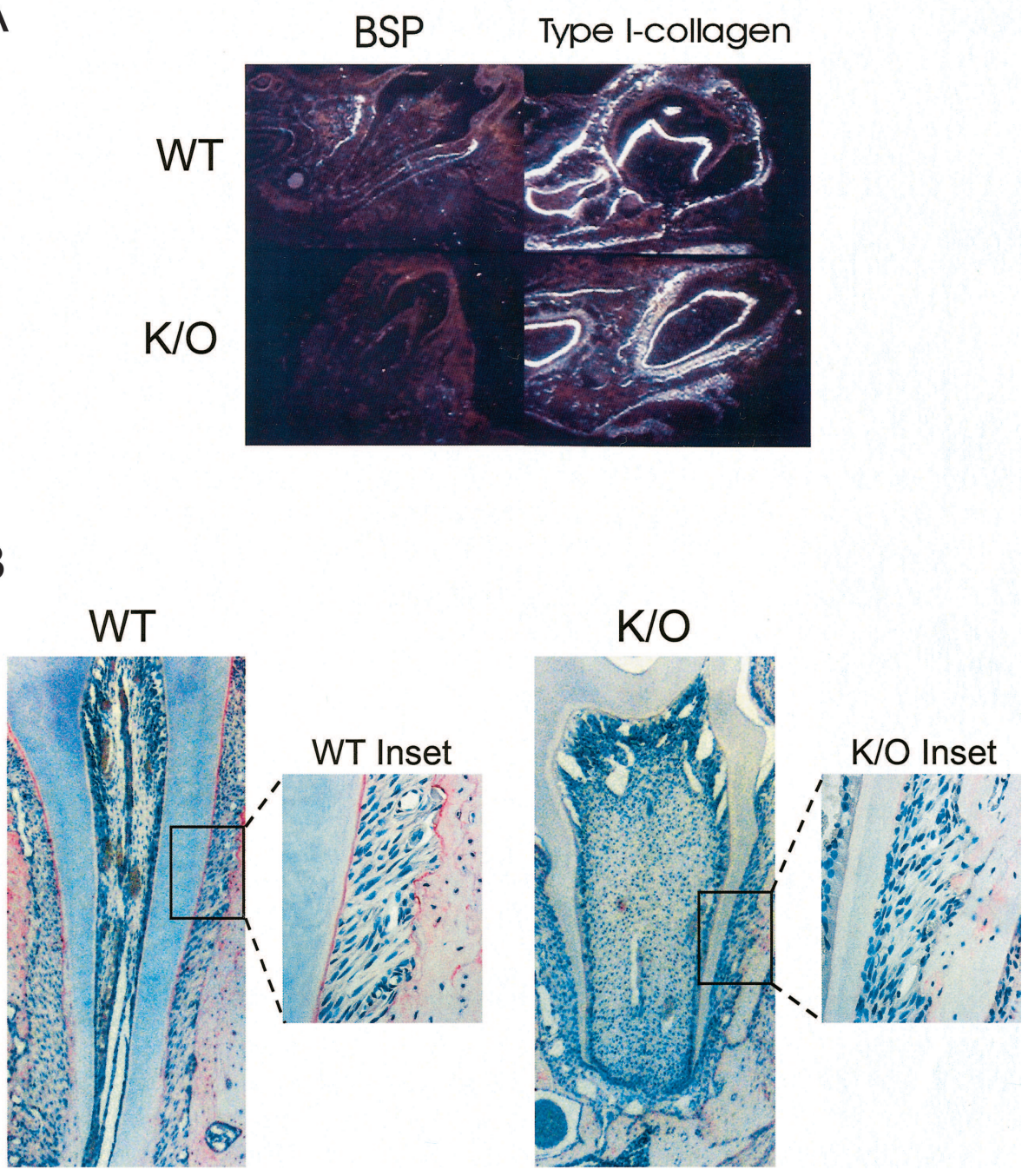

BSP expression in tissues. A) In situ hybridization for BSP and Type I collagen in mouse molars/incisors at initiation of root formation. BSP mRNA is expressed in cells along the root surface and alveolar bone in wild type (WT) tissues, whereas BSP signals are absent in knockout (KIO) tissues. Collagen mRNA expression, observed in all mesenchymal cells, is unchanged in KIO mice as compared to WT controls. Results are representative of three experiments with similar results. Although teeth probed for BSP and Type I collagen could not be matched, sections were taken from the same animals. B) Immunostaining for BSP in 33-day-old murine molars, following initiation of root formation. Low magnification photomicrographs (original magnification $\times 40$ ) show BSP localization along root surface and bone. High magnification photomicrographs (original magnification $\times 400$ ) shown in insets were taken from similar regions of the tooth root surface. Note reduction in BSP protein levels in null mice (K/O), when compared to matched wild type (WT) tissues. Results are representative of two experiments with similar results. the proliferation of cementoblasts and other cells types in vitro. ${ }^{11}$ To determine if recombinant full-length amelogenin protein has an effect similar to enamel matrix derivative, cells were treated with different concentrations of pure, recombinant $\mathrm{rp}(\mathrm{H}) \mathrm{M} 180$ and quantitated using a Coulter counter, with EMD-treated cells as a control. As shown in Figure 2, rp(H)M180 did not have a statistically significant effect on cell proliferation $(P$ $>0.05$ ), in marked contrast to EMD, which stimulated proliferation, when compared to $2 \%$ FBS control. 


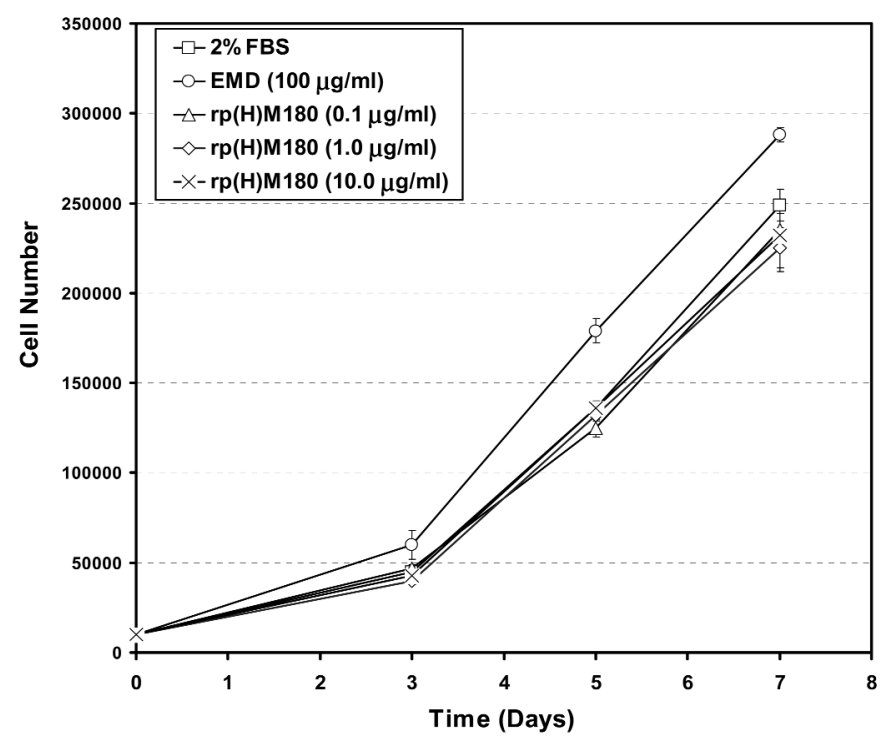

Figure 2.

Effect of amelogenin on proliferation of OCCM-30 cells. Cells were cultured in media with $2 \%$ FBS alone, EMD, or full-length recombinant amelogenin $(r p(H) M / 80)$, and cell number was determined on days 3, 5 , and 7 by Coulter counter. EMD increased cell proliferation, but treatment with $r p(H) M I 80$ showed no difference from untreated controls. Experiments were repeated three times with similar results.

\section{Dose-Dependent Effect of Amelogenin on Expression of BSP and OCN}

Northern blot analysis indicated that exogenous amelogenin exerted a regulatory effect on BSP and OCN expression. A slight increase in BSP and OCN levels was seen at $0.1 \mu \mathrm{g} / \mathrm{ml}$, whereas a marked inhibition of OCN and BSP was observed at a higher concentration, $10.0 \mu \mathrm{g} / \mathrm{ml}$ (Fig. 3A). Quantitation against ethidium bromide staining for $18 \mathrm{~S}$ rRNA showed that the reduced expression at this dose was statistically significant $(P<0.01)$ (Fig. 3B). The increase in BSP expression observed using $0.1 \mu \mathrm{g} / \mathrm{ml} \mathrm{rp}(\mathrm{H}) \mathrm{M} 180$ was not statistically significant, although this trend was observed on multiple occasions. EMD, used as a positive control, downregulated OCN, as reported previously. ${ }^{11}$ The EMD-mediated change in OCN appears to be the same as that observed for amelogenin. In contrast, two proteins of similar molecular weight to amelogenin, chymotrypsinogen and ovalbumin, had no effect on BSP and OCN mRNA levels (data not shown). The effect of amelogenin on mineral nodule formation in vitro was also analyzed using the von Kossa method (Fig. 3C). A statistically significant reduction in mineral nodule formation $(P<0.001)$ was observed with a $10.0 \mu \mathrm{g} / \mathrm{ml}$ dose of amelogenin (Fig. $3 \mathrm{D})$. This reduction in mineral formation is consistent with the dose-dependent expression profile for BSP and $\mathrm{OCN}$ and is similar to results reported previously for EMD. ${ }^{11}$
Time-Dependent Effect of Amelogenin on Expression of BSP and OCN

Figure 4 shows the temporal expression profile for BSP and $\mathrm{OCN}$, following treatment with $10.0 \mu \mathrm{g} / \mathrm{ml}$ of $\mathrm{rp}(\mathrm{H}) \mathrm{M} 180$. OCCM-30 cells were exposed to $10.0 \mu \mathrm{g} / \mathrm{ml}$ of $\mathrm{rp}(\mathrm{H}) \mathrm{M} 180$ for selected lengths of time from $30 \mathrm{~min}$ utes up to 48 hours, and BSP and OCN transcript levels were examined by Northern blot analysis. Significant down-regulation of BSP transcripts was seen at 24 hours. Downregulation of OCN was seen earlier, at 12 hours, with dramatic suppression at 24 hours. In contrast, BSP and OCN transcripts recovered by 48 hours. This does not appear to be due to a toxic effect of high-dose amelogenin on cell behavior because cell proliferation was comparable in amelogenin treated versus untreated cells.

\section{Effect of Pathway Inhibitors on BSP and OCN Gene Expression}

In initial studies focused on defining the signal transduction pathway(s) involved in the amelogenin-mediated changes in expression of BSP and OCN, the PKA and PKC pathways were examined. As seen in Figure 5A, $\mathrm{rp}(\mathrm{H}) \mathrm{M} 180$ did not elevate endogenous cAMP synthesis when compared to positive control PTHrP(1-34), suggesting that the cAMP/PKA pathway is not evoked in these cells when exposed to $\mathrm{rp}(\mathrm{H}) \mathrm{M} 180$. Further, pretreatment for 12 hours with THFA, a cell-permeable adenylyl cyclase inhibitor, was unable to reverse the inhibitory effect of $\mathrm{rp}(\mathrm{H}) \mathrm{M} 180$ on the expression of BSP and OCN (Fig. 5B), although THFA alone did produce a modest increase in the expression of both genes as reported earlier. ${ }^{36}$ Similarly, the PKC inhibitor, GF109203X, failed to prevent the downregulation of BSP and OCN when exposed to rp(H)M180 (Fig. 5B). This indicates that neither the CAMP/PKA nor the PKC pathway is responsible for the inhibitory effect on BSP and OCN expression when OCCM-30 cells are exposed to rp $(\mathrm{H}) \mathrm{M} 180$.

\section{DISCUSSION}

These studies focused on defining the response of cementoblasts to a full-length recombinant murine amelogenin (rp(H)M180) in vitro. Specifically, changes in proliferative ability, gene expression, and the formation of mineral nodules were examined. Results here indicate that $\operatorname{rp}(\mathrm{H}) \mathrm{M} 180$ alters the expression profile for both BSP and OCN in a time- and dosedependent manner, with an increase in gene transcripts at low dose and, in a response similar to that reported for EMD, ${ }^{11}$ a downregulation at higher doses. A parallel effect was observed when mineral nodule formation was examined, in which mineralization was dramatically reduced at the highest dose of $\mathrm{rp}(\mathrm{H}) \mathrm{M} 180$ used in this study $(10.0 \mu \mathrm{g} / \mathrm{ml})$. However, cementoblasts exposed to $\mathrm{rp}(\mathrm{H}) \mathrm{M} 180$ did not show increased proliferation in contrast to the enhanced proliferation 

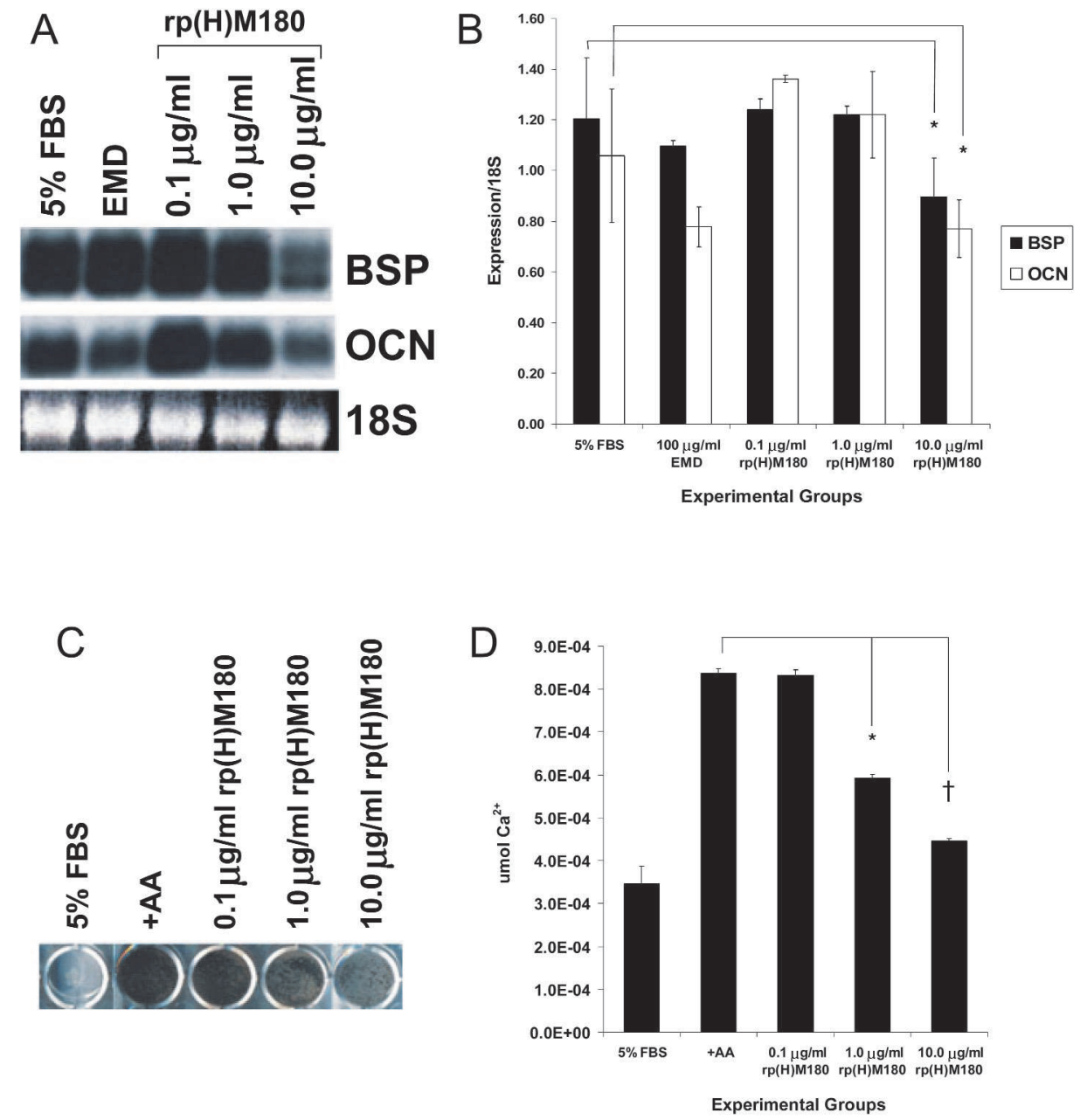

Figure 3.

Dose-dependent effect of amelogenin on OCCM-30 cells. A) Northern blot autoradiograph showing BSP and OCN mRNA levels at 8 days following treatment with $100 \mu \mathrm{g} / \mathrm{ml}$ EMD (positive control) or $\mathrm{rp}(\mathrm{H}) \mathrm{M} / 80$ at concentrations of $0.1,1.0$, and $10.0 \mu \mathrm{g} / \mathrm{ml}$. At the lowest dose, $r p(H) \mathrm{M} / 80$ slightly, but not significantly, increased transcripts for both BSP and OCN in comparison to control, whereas at the highest dose, a significant down-regulation of transcripts for both genes was observed. B) Image analysis of BSP and OCN mRNA was normalized to I 8S rRNA and shows that BSP and OCN were regulated by amelogenin in a dose-dependent fashion. $\mathbf{C}$ ) Dose-dependent effect of amelogenin on mineralization in vitro. Cells were cultured for 7 days in the presence of $50 \mu \mathrm{g} / \mathrm{ml}$ ascorbic acid (AA) and $3.0 \mathrm{mM} \beta$-glycerophosphate, along with $0.1,1.0$, or $10.0 \mu \mathrm{g} / \mathrm{ml}$ of $r p(H) M / 80$. Mineral nodule formation was significantly reduced at the two higher doses of $r p(H) M I 80,(P<0.001)$ as compared to the control $\left(^{*}\right)$, and these treatments were significantly different from each other $(P<0.001)$, as indicated in $\boldsymbol{D}$. Results are representative of four separate experiments with similar results.

seen with EMD, which is understood to consist of a mixture of enamel structural proteins. ${ }^{11}$ These results suggest that proliferative activity observed in cells exposed to EMD is not due to amelogenin, but to other yet to be identified factor(s) within EMD, such as proteolytically processed amelogenin peptides or other enamel proteins.

In situ hybridization analysis indicated that BSP expression along the tooth root surface and also within surrounding bone was dramatically reduced in the amelogenin knockout mouse. Reduced transcript expression was consistent with the immunohistochemical results that showed a reduction in BSP protein levels along the root surface when compared to an age-matched wild-type mouse. BSP is believed to play a significant role in the initiation of mineral formation because of its ability to nucleate hydroxyapatite and promote crystal deposition in vitro. ${ }^{37}$ With respect to root development, BSP is expressed by cells lining the tooth root surface (cementoblasts) and not in the periodontal ligament (PDL/fibroblasts), suggesting a key role in the initiation of cementogenesis. Recent histological analyses of tissues obtained from the amelogenin null mouse showed significant resorption of the root, accompanied by intrusion of the fibers of the periodontal ligament into the root cementum. ${ }^{25}$ While one cannot rule out that the alterations in the root are related to weakened enamel and increased stress on the tooth roots, the data presented here provide strong support for a role for amelogenins in modulating the development of periodontal tissues. These findings support the concept that epithelial-mesenchymal interactions are responsible for the development of periodontal tissues; however, until specific signaling pathways are identified, no conclusions can be drawn. The decreased expression of BSP in surrounding bone was not expected, and thus tissues were probed for BSP expression on four different occasions with similar findings. Interestingly, existing data available from studies with BSP knockout mice report a minimal phenotype; 38 however, previous studies have provided evidence that some individuals with amelogenesis imperfecta (AI) also have other skeletal disturbances. ${ }^{39}$ Al can result from defects at the genetic level that result in the expression of insufficient or defective amelogenin needed to organize the enamel organic matrix. This genetic defect in humans suggests that if amelogenin plays a signaling role during other developmental events, the lack of amelogenin may result in downstream defects, as in the developmental cascade required for formation of the skeleton. 

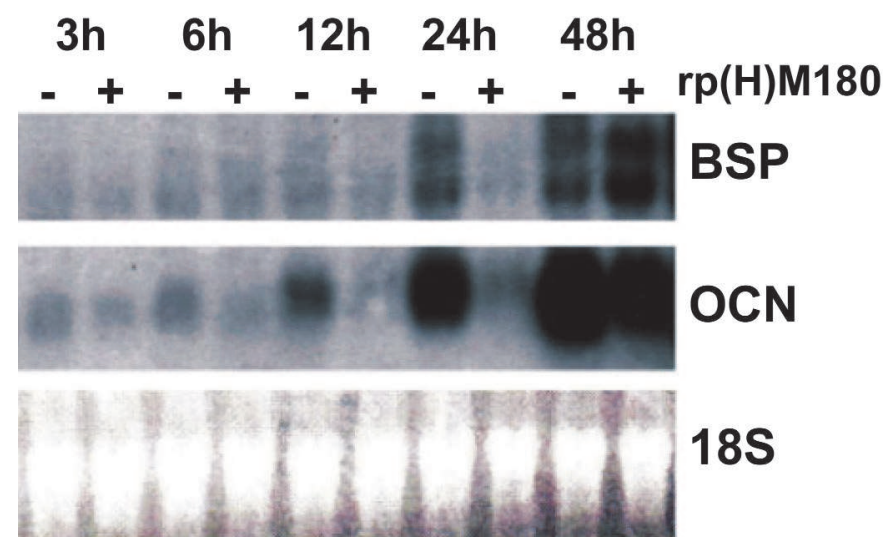

Figure 4.

Time-dependent effect of amelogenin on OCCM-30 cells. Confluent cells were treated with $10.0 \mu \mathrm{g} / \mathrm{ml}$ of $\mathrm{rp}(\mathrm{H}) \mathrm{M} / 80$ and total RNA was isolated at specific time points (0.5, 3, 6, 12, 24, and 48 hours). Northern blot analysis shows that BSP and OCN transcript levels were down-regulated, from 6 hours up to 24 hours, with recovery by 48 hours. Similar results were seen in three separate experiments.

In vitro exposure of cementoblasts to $\mathrm{rp}(\mathrm{H}) \mathrm{M} 180$ elicits a dramatic response, with a significant reduction in OCN expression observed as early as 12 hours posttreatment. Evidence indicates that OCN, which is expressed almost exclusively in mineralized tissues, e.g., bone and cementum, is a regulator of crystal growth. ${ }^{40,41}$ Our in vitro results suggest that full-length recombinant amelogenin $(\mathrm{rp}(\mathrm{H}) \mathrm{M} 180)$ can regulate gene expression in a time- and dose-dependent manner. The in vivo data also support a role for amelogenin in the regulation of genes associated with mineralized tissues, with a dramatic decrease in BSP expression in the amelogenin knockout mouse model. This is in direct contrast to the decreased expression of BSP in cells exposed to high doses of amelogenin in vitro. Although it is not surprising to observe conflicting results when comparing effects of a factor on cells/tissue in vitro versus in vivo, it is nevertheless confusing. While highly speculative, one explanation for these contrasting results may be that, at early stages of root development, amelogenin or amelogenin peptides may help promote mineralization and formation of cementum by inducing BSP expression along the root surface. Once cementum has been deposited, the local effect of amelogenin or amelogenin peptides may be to inhibit the expression of both BSP and OCN and thereby prevent the fusion of the tooth root with surrounding bone, i.e, ankylosis. By regulating both BSP and OCN, fulllength amelogenin may have a critical function as a regulator of crystal growth and mineralization.

Recent studies ${ }^{42}$ suggest that the amino- and carboxy-terminal regions of amelogenin can interact, enabling self-assembly. Eventually, this leads to the formation of nanosphere structures that are composed of several hundred amelogenin molecules. ${ }^{30,43}$ This
A

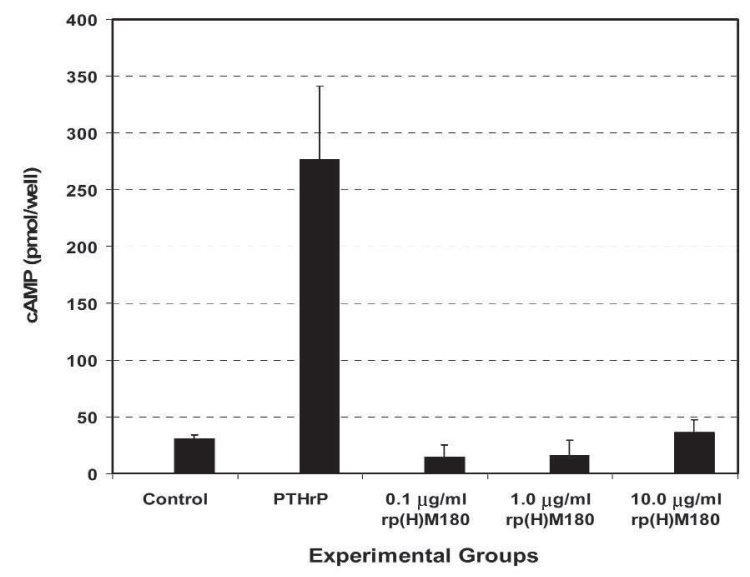

B

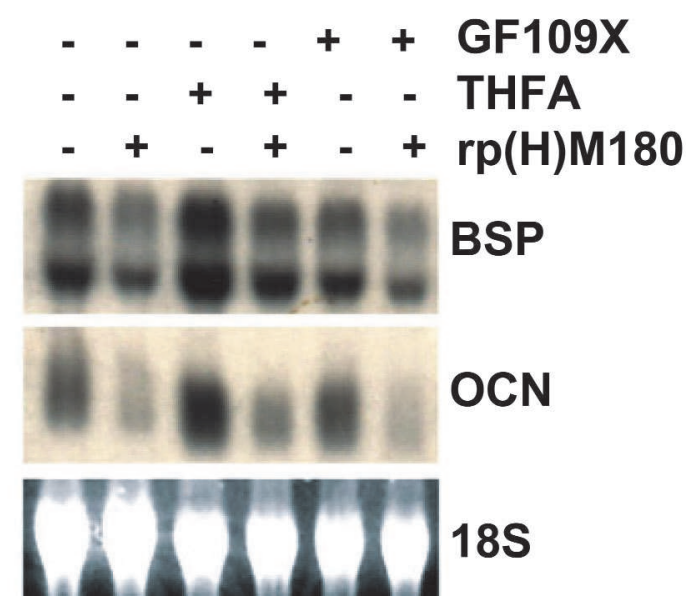

Figure 5.

Dissection of signaling pathway. A) Dose-dependent cAMP response. Cementoblasts were exposed to vehicle alone or different doses of $r p(H) M I 80(0.1,1.0$, and $10.0 \mu \mathrm{g} / \mathrm{ml})$ for 15 minutes using $10^{-7} \mathrm{M}$ PTHrP (1-34) as a positive control. CAMP stimulation was assayed and expressed as pmol cAMP/mI. While PTHrP significantly enhanced cAMP levels, no such effect was observed with any dose of $r(H) M I 80$. The experiment was performed twice, with similar results observed. B) Analysis of pathway-inhibitors on expression of BSP and OCN. Cementoblasts were pretreated with either THFA (9-(2-tetrahydrofuryl) adenine) or GFI09203X for 12 hours before being exposed to $10.0 \mu \mathrm{g} / \mathrm{ml} \mathrm{rp}(\mathrm{H}) \mathrm{M} / 80$ for an additional 12-hour time period. Northern blot analysis indicates that neither THFA nor GFI 09203X were able to reverse the down-regulation of BSP and OCN caused by $r p(H) M / 80$, suggesting that the PKA and PKC pathways are not involved in the observed repression of BSP and OCN mRNA expression. Results were reproduced on three separate occasions.

three-dimensional protein complex is then competent to guide hydroxyapatite growth. It is possible that some of the amelogenin-mediated responses seen in our cementoblast culture system may be a function of selfassembly and the resulting formation of nanosphere structures, which then act as carriers for other factors secreted by cells in the local environment, such as transforming growth factor- $\beta$ (TGF- $\beta$ ), insulin-like 
growth factors (IGFs), and BMPs. The controlled release of such factors, secreted by cells populating the local site and then incorporated into EMD or $\mathrm{rp}(\mathrm{H}) M 180$, may account for the change in gene expression observed here.

The suggested effect of one particular form of amelogenin (rp(H)M180) on cementoblasts and root formation could be viewed in two alternative ways:

1. Amelogenin, a signaling molecule, is capable of modulating expression of cementoblast-associated genes such as BSP and OCN. This suggests that periodontal development is a result of complex epithelialmesenchymal interactions. Unfortunately, the results to date suggest that the more traditional signaling pathways are not involved. Or, alternatively,

2. Amelogenin, a structural protein, is capable of acting as a nanostructured support or carrier material for other unknown factors secreted by cells and then incorporated into the assembled amelogenin complex. Subsequently, such matricrine factors released by the carrier (amelogenin) promote periodontal development.

It is clear that a better understanding of these processes is necessary. In the future, we plan to establish the mechanism(s) by which full-length amelogenin alters cementoblast behavior and to define the role of amelogenin proteolytic products and leucine rich amelogenin peptides (LRAPs) in the regulation of cementoblast function. LRAPs are splice variants of amelogenin that lack the hydrophobic part of the fulllength protein. Consequently, they have significantly different biochemical properties that may contribute to some of the variation in signaling effects of amelogenin reported previously. ${ }^{22}$ Furthermore, data suggest that the amino terminal end of the full-length amelogenin protein may be responsible for the peptide interactions that lead to the formation of the selfassembled nanospheres, while the $\mathrm{C}$-terminal portion provides stability and homogeneity. ${ }^{29}$ The interaction between the $\mathrm{N}$-terminal and $\mathrm{C}$-terminal peptides is believed to be critical for biomineralization. ${ }^{29}$ To address these issues, we have initiated studies using engineered $\mathrm{rp}(\mathrm{H}) \mathrm{M} 180$ protein isoforms, where selected domains of full-length amelogenin have been deleted. Information from these studies, along with experiments designed to define amelogenin-specific receptors, will help to clarify the mechanism by which amelogenin regulates key markers associated with mineralization. Defining the role for the various amelogenins in controlling the activity of mesenchymal cells in vitro will provide essential information required to design regenerative therapies targeted at enhancing formation of mineralized tissues, e.g., root cementum and bone, while maintaining a functional PDL region.

\section{ACKNOWLEDGMENTS}

The authors would like to thank Amy J. Koh for her help with the CAMP assays. This work was supported in part by grants from the NIH NIDCR R01-DE09532
(MJS), DE11089 (CWG), Z01-DE00698-1(ABK), and DE13045 (MLS).

\section{REFERENCES}

1. Tucker A, Matthews K, Sharpe P. Transformation of tooth type induced by inhibition of BMP signaling. Science 1998; 282:1136-1138.

2. Peters H, Balling R. Teeth-Where and how to make them. Trends Genet 1999;15:59-65.

3. Jernvall J, Thesleff I. Reiterative signaling and patterning during mammalian tooth morphogenesis. Mech Dev 2000; 92:19-29.

4. Maas R, Bei M. The genetic control of early tooth development. Crit Reu Oral Biol Med 1997;8:4-39.

5. Bosshardt D, Nanci A. Immunolocalization of epithelial and mesenchymal matrix constituents in association with inner enamel epithelial cells. J Histochem Cytochem 1998; 46:135-142.

6. Schonfeld D, Slavkin H. Demonstration of enamel matrix protein on root-analogue surfaces of rabbit permanent incisor teeth. Calcif Tissue Res 1977;24: 223-229.

7. Slavkin H. Towards a cellular and molecular understanding of periodontics. Cementogenesis revisited. $J$ Periodontol 1976;47:249-255.

8. Hammarstrom L, Alatli I, Fong C. Origins of cementum. Oral Dis 1996;2:63-69.

9. Lindskog S, Hammarstrom L. Formation of intermediate cementum. III: 3H-tryptophan and $3 \mathrm{H}$-proline uptake into the epithelial root sheath of Hertwig in vitro. J Craniofac Genet Deu Biol 1982;2:171-177.

10. Fong C, Slaby I, Hammarstrom L. Amelin: An enamelrelated protein, transcribed in the cells of epithelial root sheath. J Bone Miner Res 1996;11:892-898.

11. Tokiyasu Y, Takata T, Saygin E, Somerman M. Enamel factors regulate expression of genes associated with cementoblasts. J Periodontol 2000;71:1829-1839.

12. Lyngstadaas S, Lundberg E, Ekdahl H, Andersson C, Gestrelius S. Autocrine growth factors in human periodontal ligament cells cultured on enamel matrix derivative. J Clin Periodontol 2001;28:181-188.

13. Gestrelius S, Andersson C, Lidstrom D, Hammarstrom L, Somerman $M$. In vitro studies of periodontal ligament cells and enamel matrix derivative. J Clin Periodontol 1997;24: 685-692.

14. Hammarstrom L. Enamel matrix, cementum development, and regeneration. J Clin Periodontol 1997;24: 658-668.

15. Hammarstrom L. The role of enamel matrix proteins in the development of cementum and periodontal tissues. Ciba Found Symp 1997;205:246-255.

16. Gestrelius S, Lyngstadaas S, Hammarstrom L. Emdogain-periodontal regeneration based on biomimicry. Clin Oral Investig 2000;4:120-125.

17. Simmer J. Alternative splicing of amelogenins. Connect Tissue Res 1995;32:131-136.

18. Lau E, Mohandas T, Shapiro L, Slavkin H, Snead M. Human and mouse amelogenin gene loci are on the sex chromosomes. Genomics 1989;4:162-168.

19. Paine M, Zhu D, Luo W, et al. Enamel biomineralization defects result from alterations to amelogenin self-assembly. J Struct Biol 2000;132:191-200.

20. Paine $M$, Snead $M$. Protein interactions during assembly of the enamel organic extracellular matrix. J Bone Miner Res 1997;12:221-227.

21. Nebgen D, Inoue H, Sabsay B, Wei K, Ho C-S, Veis A. 
Identification of the chondrogenic-inducing activity of bovine dentin (bCIA) as a low-molecular mass amelogenin polypeptide. J Dent Res 1999;78:1484-1494.

22. Veis A, Tompkins K, Alvares K, et al. Specific amelogenin gene splice products have signaling effects on cells in culture and in implants in vivo. J Biol Chem 2000;275: 41263-41272.

23. Ganss B, Kim R, Sodek J. Bone sialoprotein. Crit Rev Oral Biol Med 1999;10:79-98.

24. MacNeil R, Sheng N, Strayhorn C, Fisher L, Somerman $M$. Bone sialoprotein is localized to the root surface during cementogenesis. J Bone Miner Res 1994;9:1597-1606.

25. Hatakeyama J, Sreenath T, Hatakeyama Y, et al. The receptor activator of nuclear factor-kappa B ligand-mediated osteoclastogenic pathway is elevated in amelogenin null mice. J Biol Chem 2003;278:35743-35748.

26. Gibson C, Yuan Z, Hall B, et al. Amelogenin-deficient mice display an amelogenesis imperfecta phenotype. J Biol Chem 2001;276:31871-31875.

27. D'Errico J, Berry J, Ouyang H, Strayhorn C, Windle J, Somerman M. Employing a transgenic animal model to obtain cementoblasts in vitro. J Periodontol 2000;71: 63-72.

28. D'Errico J, Ouyang H, Berry J, et al. Immortalized cementoblasts and periodontal ligament cells in culture. Bone 1999;25:39-47.

29. Moradian-Oldak J, Paine M, Lei Y, Fincham A, Snead M. Self-assembly properties of recombinant engineered amelogenin proteins analyzed by dynamic light scattering and atomic force microscopy. J Struct Biol 2000;131:27-37.

30. Young M, Ibaraki K, Kerr J, Lyu M, Kozak C. Murine bone sialoprotein (BSP): cDNA cloning, mRNA expression, and genetic mapping. Mamm Genome 1994;5:108-111.

31. McCauley L, Koh A, Beecher C, Cui Y, Rosol T, Franceschi R. PTH/PTHrP receptor is temporally regulated during osteoblast differentiation and is associated with collagen synthesis. J Cell Biochem 1996;61:638-647.

32. Xie W, Rothblum L. Rapid, small-scale RNA isolation from tissue culture cells. Biotechniques 1991;11:323327.

33. Celeste A, Rozen V, Bueker J, Kriz R, Wang E, Wozney J. Isolation of the human gene for bone gla protein utilizing mouse and rat cDNA clones. EMBO J 1986;5:1885-1890.

34. Marsh M, Munne A, Vogel J, Cui Y, Franceschi R. Mineralization of bone-like extracellular matrix in the absence of functional osteoblasts. J Bone Miner Res 1995;10: 1635-1643.

35. Balint E, Szabo P, Marshall C, Sprague S. Glucose-induced inhibition of in vitro bone mineralization. Bone 2001;28: 21-28.

36. Ouyang H, McCauley L, Berry J, Saygin N, Tokiyasu Y, Somerman M. PTHrP regulates extra-cellular matrix gene expression in cementoblasts and inhibits cementoblast mediated biomineralization in vitro. J Bone Miner Res 2000;15:2140-2153.

37. Hunter G, Goldberg H. Nucleation of hydroxyapatite by bone sialoprotein. Proc Natl Acad Sci USA 1993;90: 8562-8565.

38. Aubin J, Gupta A, Zirngibl R, Rossant J. Bone sialoprotein knockout mice have bone abnormalities. Bone 1995; 17:558.
39. Backman B, Adolfsson U. Craniofacial structure related to inheritance pattern in amelogenesis imperfecta. Am J Orthod Dentofacial Orthop 1994;105:575-582.

40. Karsenty G. Bone formation and factors affecting this process. Matrix Biol 2000;19:85-89.

41. Boskey A, Gadaleta S, Gundberg C, Doty S, Ducy P, Karsenty G. Fourier transform infrared microspectroscopic analysis of bones of osteocalcin-deficient mice provides insight into the function of osteocalcin. Bone 1998;23: 187-196.

42. Paine M, Krebsbach P, Chen L, et al. Protein-to-protein interactions: Criteria defining self-assembly of the enamel organic matrix. J Dent Res 1998;77:496-502.

43. Fincham A, Moradian-Oldak J, Diekwisch T, et al. Evidence for amelogenin nanospheres as functional components of secretory-stage enamel matrix. J Struct Biol 1995;112:103-109.

Correspondence: Dr. Martha J. Somerman, Department of Periodontics, University of Washington School of Dentistry, Seattle, WA 98195-7444. E-mail: somerman@u.washington.edu.

Accepted for publication March 14, 2003. 